\title{
Removal of Salicylic Acid from Aqueous Solutions Using Various Electrodes and Different Connection Modes by Electrocoagulation
}

\author{
Fuat Ozyonar*, Sümeyye Aksoy \\ Department of Environmental Engineering, Cumhuriyet University, 58140 Sivas, Turkey \\ *E-mail: fozyonar@ cumhuriyet.edu.tr
}

doi: $10.20964 / 110454$

Received: 10 February 2016 / Accepted: 3 March 2016 / Published: 1 April 2016

\begin{abstract}
Removal of salicylic acid (SA) from aqueous solutions using hybrid aluminum and iron electrodes (eight different combinations) and three different connection modes (monopolar parallel (MP-P), Monopolar series (MP-S) and bipolar series (BP-S)) by electrocoagulation was investigated in this study. The effects of electrocoagulation parameters such as hybrid electrode combination, initial $\mathrm{pH}$, current density, initial salicylic acid concentration, air injection flow, solution conductivity and connection mode on SA and COD removal efficiencies were evaluated. Optimum operational conditions at $10 \mathrm{~min}$ operating time were found to be as: Al-Al-Al-Al (anode-cathode-anode-cathode) electrode combination, the initial $\mathrm{pH}$ of 6 , current density of $50 \mathrm{~A} / \mathrm{m}^{2}$, salicylic acid concentration of $100 \mathrm{mg} / \mathrm{L}$, air injection mode of $2 \mathrm{~L} / \mathrm{min}$ and connection mode of monopolar series (MP-S). Under these conditions, removal efficiencies for salicylic acid and COD were respectively observed as $95.1 \%$ and $85.97 \%$. Moreover, the UV absorbance was determined before and after the treatments by electrocoagulation (EC) process. The operating costs including electrodes, energy and chemicals were calculated as $0.0156 € / \mathrm{m}^{3}$. Sludge generation of EC process was also analyzed by scanning electron microscope (SEM) imaging, Fourier Transform Infrared Spectroscopy (FT-IR), XRD (Xraydiffraction) and amorphous $\mathrm{Al}$ hydroxides were encountered in the sludge. As to conclude, electrocoagulation through different electrode combinations and connections modes was found to be quite efficient for removal of salicylic acid from aqueous solutions.
\end{abstract}

Keywords: Electrocoagulation, Removal of Salicylic acid, Hybrid Fe-Al electrode, Electrode connection mode, Operating cost.

\section{$\underline{\text { FULL TEXT }}$}

(C) 2016 The Authors. Published by ESG (www.electrochemsci.org). This article is an open access article distributed under the terms and conditions of the Creative Commons Attribution license (http://creativecommons.org/licenses/by/4.0/). 